\title{
Spatial Analysis of Soybean Plant Height and Plant Canopy Temperature Measured with On-the-Go Tractor Mounted Sensors
}

\author{
Reginald S. Fletcher1', Daniel K. Fisher² \\ ${ }^{1}$ Crop Production Systems Research Unit, Agricultural Research Service, United States Department of Agriculture, Stoneville, \\ USA \\ ${ }^{2}$ Sustainable Water Management Research Unit, Agricultural Research Service, United States Department of Agriculture, \\ Stoneville, USA \\ Email: reginald.fletcher@usda.gov, daniel.fisher@usda.gov
}

How to cite this paper: Fletcher, R.S. and Fisher, D.K. (2019) Spatial Analysis of Soybean Plant Height and Plant Canopy Temperature Measured with On-the-Go Tractor Mounted Sensors. Agricultural Sciences, 10, 1486-1496.

https://doi.org/10.4236/as.2019.1011109

Received: September 25, 2019

Accepted: November 24, 2019

Published: November 27, 2019

Copyright $\odot 2019$ by author(s) and Scientific Research Publishing Inc. This work is licensed under the Creative Commons Attribution International License (CC BY 4.0).

http://creativecommons.org/licenses/by/4.0/

\begin{abstract}
There is a growing interest in the Open Ag community to use inexpensive sensors controlled by open-source software to measure plant height and plant canopy temperature of agricultural crops. Plant height and plant canopy temperature are key indicators of plant health. This research study reports on an ongoing research initiative to test a compact and inexpensive mobile sensor to measure plant height and plant canopy temperature. The system is controlled by open source software and hardware. The specific objectives for this study were to analyze the relationship between plant height and plant canopy temperature of soybeans (Glycine max L.) measured with the mobile system and to analyze the spatial correlation of the plant height and plant canopy temperature measurements. Data were collected in a soybean plot in 2018 and 2019. Descriptive statistics, Pearson correlation, and geostatistical techniques were used to evaluate the data. A negative statistically significant $(p \leq 0.05)$ relationship was observed between the plant height and the plant canopy temperature measurements $(\mathrm{r}=-0.54,2018 ; \mathrm{r}=-0.37,2019)$. Also, both parameters were spatially correlated; however, plant height had a greater spatial continuity than plant canopy temperature. Furthermore, similar patterns were observed for the in-field variability of the plant height and plant temperature maps derived via kriging. Similarities in plant height and plant canopy temperatures were observed from one year to the next, suggesting that the sensor technologies could be used as a historical record for monitoring growth patterns in soybean fields. The sensors and techniques used in this study can be easily adapted to other crops, thus providing two important layers for monitoring plant growth and potentially plant stress.
\end{abstract}




\section{Keywords}

Glycine max, Ultrasonic Sensors, Infrared Thermometer, Correlation, In-Field Variability

\section{Introduction}

Plant height and plant canopy temperature are two important plant parameters in agricultural production systems. They are key indicators of plant growth, development, and yields [1] [2] [3]. Plant height and/or plant canopy temperature sensors have been developed by researchers to record data while mounted on a mobile platform [4] [5] [6]. Mobile plant height and/or plant canopy temperature sensors have been used to obtain measurements for various crops, including sugarcane (Saccharum officinarum L.), cotton (Gossypium hirtusuum L.), corn (Zea mays L.), soybean (Glycine max L.), wheat (Triticum aestivum L.), and wild blueberry (Vaccinium angustifolium Aiton) [4] [6] [7] [8].

Recently, the agricultural community has become interested in the opensource market for sensor development because the user can share and modify system components to meet their needs. Open-source technologies have shown promise for the following agriculture applications, monitoring water levels in evaporation pans used in evaporation studies and irrigation scheduling [9], checking soil water content and multiple soil air-vegetation parameters [10], monitoring air humidity, air temperature, soil moisture, and soil temperature [11], and tracking meteorological conditions associated with downy mildew (Hyaloperonospora brassicae) development in vineyards and determining the most suitable time to treat downy mildew disease [12].

Recently, [5] developed a plant-canopy monitoring system with inexpensive sensors and open-source software, demonstrated how the system components worked, and discussed data output and potential applications of the data as a survey tool. The sensor system can be easily mounted on an agricultural vehicle such as a tractor to record plant height, plant canopy temperature, and location data as the device is moved throughout the field. The components for their four-row system only cost $\$ 292.00$, and fabrication of the parts took only four hours. Currently, information is lacking on the relationship between plant height and plant temperature data recorded with the sensors on that system and on the potential of using the system to develop maps showing in-field variability of plant height and plant canopy temperature. This research study builds on the work of [5] and focuses on the following objectives: 1) analyze the relationship between plant height and plant canopy temperature of soybeans measured with on-the-go ultrasonic and infrared thermometers and 2) analyze the spatial variability of the plant height and plant canopy temperature measurements. Positive findings from this study will further support using inexpensive systems and 
open-source software to monitor plant parameters in soybean production systems.

\section{Materials and Methods}

\subsection{Research Site}

A 2-haplot $\left(33.448360^{\circ}\right.$ latitude, $-90.869928^{\circ}$ longitude) located at the United States Department of Agriculture, Agriculture Research Service, Mechanization Farm was used for this study. The farm is in Washington County, MS and is located approximately $5.8 \mathrm{~km}$ northeast of the city of Stoneville, MS (Figure 1). The study plot is referred to as Field 14 (Figure 1). The field consisted of Sharkey clay, (0.5\% to $2 \%$ slope, very-fine, smectitic, thermic Chromic Epiaquerts) and Tunica clay ( $0 \%$ to $2 \%$ slope, Clayey over loamy, smectitic over mixed, superactive, nonacid, thermic Vertic Epiaquepts).The average rainfall, maximum temperature, and minimum temperature of Washington County, MS are 135 $\mathrm{cm}, 33.6$ degrees Celsius in July, and 2.2 degrees Celsius in January, respectively [13]. Major crops grown in Washington County include soybeans, corn, cotton, rice (Oryza sativa L.), and wheat [14].

The soybean cultivars planted in the field for the 2018 and 2019 growing seasons were Dyna-Gro "31RY45" and Asgrow "AG45X", respectively. The following are the agronomic traits of Dyna-Gro "31RY45": 1) maturity group-4.5, 2) herbicide tolerance-roundup ready 2 yield trait, 3) flower color-purple, 4) pubescence color-light tawny, 5) pod color-brown, 6) hilum color-black, and 7) growth habit-indeterminate. Asgrow "AG45X8" has the following plant characteristics: 1) maturity group-4.5,2) herbicide tolerance-roundup ready 2

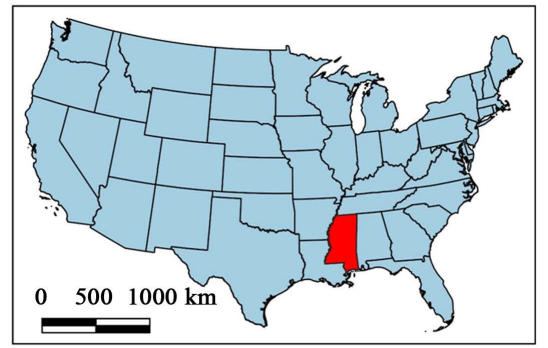

(a)

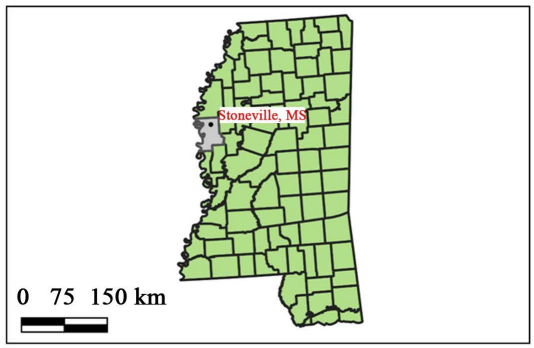

(b)

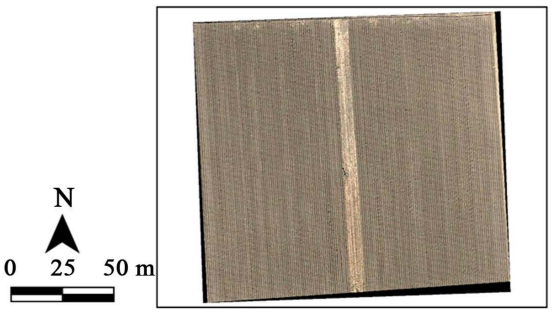

(c)

Figure 1. (a) A map of the United States showing the state of Mississippi in red; (b) Mississippi State map showing Washington County in gray and the location of Stoneville, MS; (c) Close up of the research plot $\left(33.448360^{\circ}\right.$ latitude, $-90.869928^{\circ}$ longitude) located on the Mechanization Farm, approximately $5.8 \mathrm{~km}$, northeast of Stoneville. 
xtend (i.e., dicamba and glyphosate herbicide tolerance), 3) flower color-purple, 4) pubescence color-light tawny, 5) pod color-brown, 6) hilum color-black, and 7) growth habit-indeterminate. The planting dates were May 2, 2018 and 2019. For the 2018 growing season, the field contained a twelve-row buffer of corn planted on the east and west sides of the plot and a 15-m buffer of corn planted on the north end of the plot. Therefore in 2018, plant mapping was limited to the row area planted to soybeans.

\subsection{Data Collection}

The sensor described by [5] was used in this study. It consisted of a batterypowered, microcontroller-based system containing a Bluetooth radio, global positioning receiver, four infrared temperature sensors (plant canopy temperature measurements), four ultrasonic distance sensors (plant height measurement), micro secure digital card, and voltage regulation components. The sensors were installed in plastic enclosures, with one temperature and one ultrasonic sensor in each enclosure, with enclosures mounted at 1-m spacings along a horizontal aluminum channel. The system was then mounted on the front of an agricultural spray vehicle to collect data simultaneously from four crop rows. Prior to data collection in the field, the sensor system was driven to a bare soil area adjacent to the study plot; the distance between the plant height sensors and bare ground area was measured to establish the maximum height of the sensor above ground level, the reference distance. This information was used to calculate the plant height measurements obtained with the ultrasonic sensor in the field. Additionally, the distance between the sensor and bare ground level was measured with a tape measure to evaluate the accuracy of plant height sensors. The plant height sensors measurements were $\pm 2 \mathrm{~cm}$ of the manual measurements. In postprocessing of the data, the plant height was determined by subtracting the measured distance obtained from the plant canopy sensor during field measurements from the bare ground reference-distance measurement.

The study plot was divided into four-row transects for data collection. Figure 2 shows an example of the sensor system collecting data from one of the

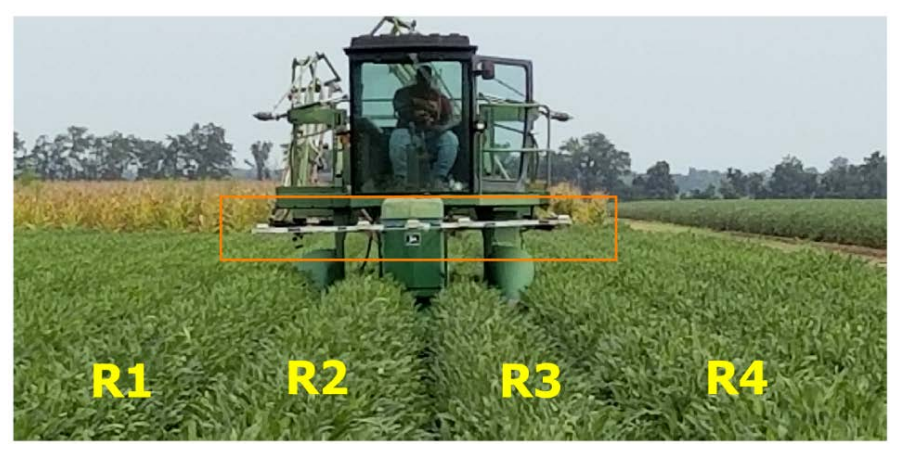

Figure 2. Data collection (August 8, 2019) of soybeans with mobile plant height and plant canopy temperature system-enclosed in orange square. R1, R2, R3 and R4-rows 1 - 4 of transect. Vehicle is traveling in the north to south direction. 
four-row transects. Note the sensing system consists of four sensors; each sensor was collecting plant height and plant temperature data from one of the rows within the transect. Data were collected on July 26, 2018 and August 8, 2019 between 13:48 to 14:56 hrs. and 9:17 to 10:16 hrs. daylight savings time, respectively.

\subsection{Post Processing}

For further analysis, we only used data collected from the two center sensors. Measurements from these sensors coincide with other field sensors that are being tested on this plot. Data were cleaned prior to further analysis including removal of inaccurate values and points that were collected outside of the field boundary. Then, the plant height and plant canopy temperature data were averaged for the two center sensors.

\subsection{Statistical Analysis}

Descriptive statistics (i.e., minimum, maximum, mean, standard deviation, skewness), histograms, and frequency distribution plots were used to evaluate the normality and variability of the plant height and the plant canopy temperature datasets. Pearson correlation $(p \leq 0.05)[15]$ was employed to determine the relationship between the plant height and plant canopy temperature measurements. The R software ["Action of the Toes" [16]] was used to calculate the descriptive statistics and the Pearson correlation coefficient.

\subsection{Spatial Statistics}

Geostatistical techniques including variogram models and kriging were explored to determine the spatial correlation of plant height and plant canopy temperature measurements and to derive maps of plant height and plant canopy temperature, respectively. Isotropic and anisotropic ( $0,45,90$, and 135 degrees) variograms were evaluated to derive the model for describing and mapping the spatial variation of the plant parameters. Spherical, linear, exponential, and gaussian variogram models were tested. They were selected by using a combination of residual sums of squares, coefficient of determination, and manual evaluation of the model fit to the calculated variogram. Model accuracy was tested with the leave-one-out cross-validation method provided by the software. After selecting the appropriate variogram model, we created maps via block kriging (i.e., ordinary kriging) with a window size of $8 \times 8$ meters. Variogram model selection, evaluation, and block kriging were completed with the Geostatistics for Environmental Science software (GS+, version 10, Gamma Design, Plainwell, MI). Geostatistical techniques are commonly used to model and map agricultural variables; for a more detailed description of geostatistical methods, see Oliver and Webster [17] [18]. Block kriged data were imported into the QGIS software to develop the final maps (Madeira, Version 3.4, Long term release, [19]). 


\section{Results}

\subsection{Summary Statistics and Correlation Measurements}

Descriptive statistics are summarized in Table 1 for the 2018 plant height and plant canopy temperature measurements. One thousand eighty-two points were used for the data analysis. A difference of $65.1 \mathrm{~cm}$ was observed in the plant height; whereas, a difference of $11.7^{\circ} \mathrm{C}$ occurred for the plant canopy temperature.

In 2019, 965 points were used for data analysis (Table 1). The minimum and maximum values indicated an in-field variability of $40 \mathrm{~cm}$ in plant height. Plant canopy temperature was less variable; only a $2^{\circ} \mathrm{C}$ difference between the minimum and maximum values was observed. Overall, the 2019 dataset was less variable than the 2018 dataset.

Moderate to weak statistically significant $(p \leq 0.05)$ negative correlations were observed between the plant height and the plant canopy temperature (Table 2). The best correlation occurred for the 2018 data measurements, indicating the strength of the relationship can change from one year to the next.

\subsection{Variogram Models}

The plant height and the plant canopy temperature data were spatially correlated (Table 3). Isotropic exponential models best described the plant height spatial correlation for the 2018 and 2019 field measurements and the plant canopy temperature measurements for the 2019 dataset. An isotropic spherical model best described the spatial variability of the plant canopy temperature in 2018 .

Table 1. Descriptive statistics for plant height and plant canopy temperature recorded by on-the-go plant height and plant canopy temperature sensors at Field 14, Mechanization Farm, Stoneville, MS.

\begin{tabular}{ccccccccc}
\hline \multicolumn{1}{c}{ Date } & Variable & Points & Min $^{\mathrm{a}}$ & Max & Mean & SD & Var & Skew \\
\hline July 26, 2018 & PLH & 1082 & 35.9 & 101.0 & 70.1 & 11.8 & 140.1 & -0.2 \\
& PLCT & 1082 & 32.0 & 43.7 & 37.6 & 2.3 & 5.2 & -0.2 \\
August 8, 2019 & PLH & 965 & 55.5 & 96.4 & 77.2 & 7.7 & 59.9 & -0.4 \\
& PLCT & 965 & 28.2 & 30.2 & 29.1 & 0.4 & 0.1 & 0.3 \\
\hline
\end{tabular}

${ }^{\text {aPLH}}$-Plant height; PLCT—plant canopy temperature; Min—minimum; Max—maximum; SD—standard deviation; Var-variance; and Skew—skewness.

Table 2. Pearson correlation between plant height and plant canopy temperature recorded by on-the-go plant height and plant canopy temperature sensors at Field 14, Mechanization Farm, Stoneville, MS.

\begin{tabular}{cc}
\hline Date & Correlation \\
\hline July 26, 2018 & $-0.54^{\star a}$ \\
August 8, 2019 & $-0.37^{\star}$
\end{tabular}

${ }^{a}$ Statistically significant at $p \leq 0.05$. 
Table 3. Variogram parameters for plant height and plant canopy temperature recorded by on-the-go plant height and plant canopy temperature sensors at Field 14, Mechanization Farm, Stoneville, MS.

\begin{tabular}{cccccccc}
\hline Date & Variable & Model & Nugget & Sill & Range $(\mathrm{m})$ & RSS $^{\mathrm{a}}$ & $\mathrm{r}^{2}$ \\
\hline July 26, 2018 & PLH & Exponential & 103.2 & 206.5 & 102.8 & 11.9 & 0.994 \\
& PLCT & Spherical & 1.2 & 6.4 & 92.2 & 0.066 & 0.996 \\
August 8, 2019 & PLH & Exponential & 18.9 & 93.5 & 71.4 & 19.7 & 0.992 \\
& PLCT & Exponential & 0.07 & 0.16 & 21.0 & 0.0001 & 0.972 \\
\hline
\end{tabular}

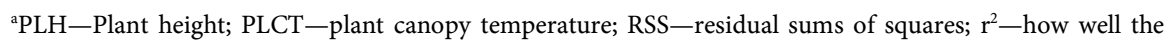
model fits the variogram.

The spatial correlation of plant height was $102.8 \mathrm{~m}$ and $71.4 \mathrm{~m}$ for 2018 and 2019, respectively. The spatial correlation for temperature was $92.2 \mathrm{~m}$ and $21 \mathrm{~m}$ for the 2018 and 2019 datasets, respectively. Plant height was spatially correlated over a longer distance than the plant canopy temperature.

\subsection{Plant Height and Plant Canopy Temperature Maps}

Plant height and plant canopy temperature maps derived from block kriging are shown in Figure 3. In 2018, the tallest soybean plants were observed in the southwest region of the plot; shorter plants were detected in the mid central and southeast sections of the field (Figure 3(a)). The plant canopy temperature in-field variability pattern was similar to the plant height measurements' in-field variability pattern (Figure $3(\mathrm{~b})$ ). The lowest canopy temperature occurred in the southwest region of the plot where the tallest soybean plants were mapped.

For the 2019 results, the tallest soybean plants occurred in the eastern and the southwestern sections of the plot (Figure 3(c)). There was a general agreement in the variability patterns of plant height and plant canopy temperature in that increases in plant height were associated with decrease in plant canopy temperature (Figure 3(c) and Figure 3(d)). The plant height differences observed in the southwest section of the field were consistent with the plant height differences observed in 2018. Furthermore, in 2019, the shortest plants were observed in the northern section of the field plot.

\section{Discussion}

The location and number of samples are important for understanding and mapping the spatial variability of plant and soil parameters. Within approximately $1.5 \mathrm{hrs}$, the mobile system acquired approximately 1000 plant height and plant canopy temperature measurements to use for studying the variability of those components. Additionally, the sensors can acquire measurements at any location within a field that is accessible by tractor.

Overall a negative relationship was observed between plant height and plant canopy temperature (Table 2). Reference [20] also observed a negative relationship between plant height and plant canopy temperature for similar sensors used 


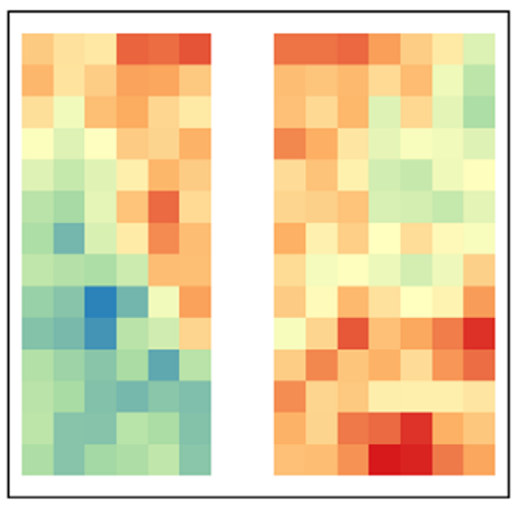

(a)

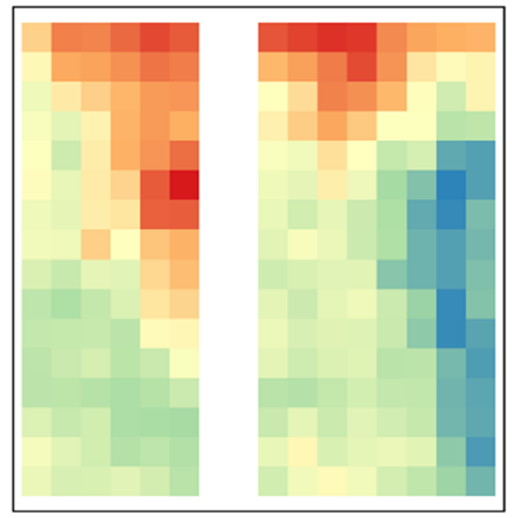

(c)

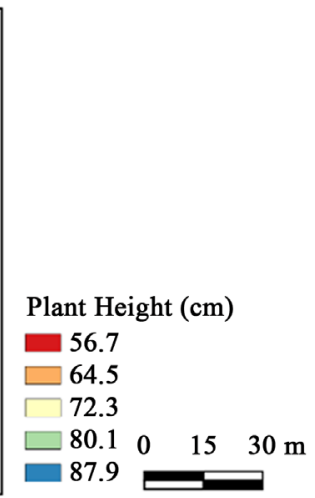

87.9

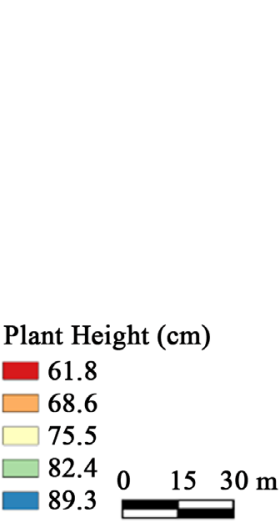

89.3

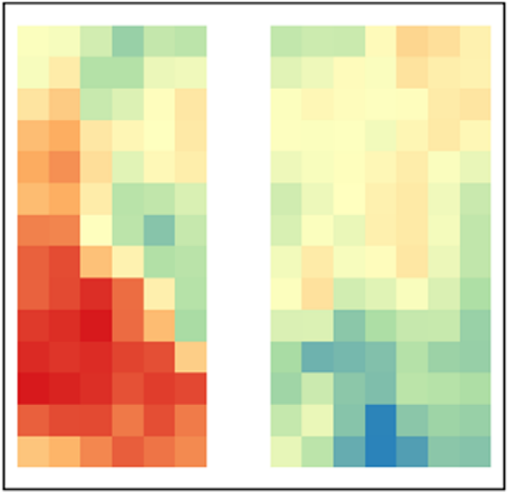

(b)
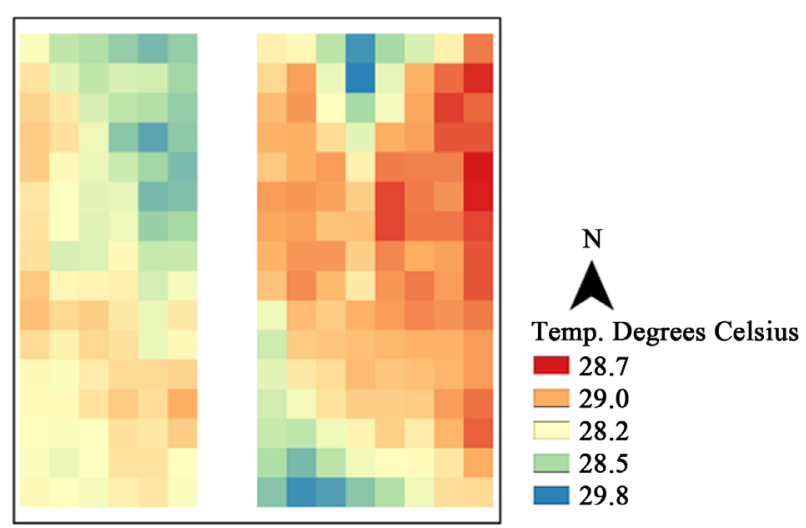

(d)

Figure 3. Block kriged thematic maps, Field 14, Mechanization Farm, Stoneville, MS: (a) plant height-July 26, 2018; (b) plant canopy temperature-July 26, 2018; (c) plant height-August 8, 2019; and (d) plant canopy temperature-August 8, 2019.

for a soybean and wheat phenotyping study focusing on plant breeding. The difference between our study and their study was that our goal was to simulate using the plant height and plant canopy temperature system in normal farming operations. With that aspect in mind, the average speed of the tractor recorded by the global positioning system sensor was $5 \mathrm{~km} \cdot \mathrm{hr}^{-1}$ during data collection. Future research initiatives need to focus on speeds commonly used by agricultural producers because the final goal is to be able to use this system simultaneously with other farming operations implements.

For geostatistical applications, [17] [18] indicated that 100 to 150 points are needed to develop good variogram models for creating maps via kriging. The sensing system collected more than enough points to meet that criteria. Geostatistical analysis showed that plant height and plant canopy temperature variation was spatially dependent for both years of data collection. The plant height was spatially correlated for longer distances than the plant canopy temperature for both years (see range parameters in Table 3). Maps derived from kriging indicated that the plot could be divided into zones, which was consistent with other researchers using on-the-go sensors to measure plant canopy height and volume [21]. 
The differences in plant height observed on the maps were verified during ground-truthing of the field, thus justifying accuracy and potential use of the system as a survey tool. Furthermore, we observed consistency in the plant height and the plant temperature variability from one year to the next. Thus, measurements obtained with this system can serve as a historical record of temperature and plant growth patterns observed in soybean fields.

\section{Conclusion}

The tractor is the primary tool used to get things done on a farm. Mounting sensors on it can be a valuable way to collect information about plant physical parameters. In this study, we continued on-going research to test inexpensive tractor-mounted plant height and plant canopy temperature sensors to map plant height and plant canopy temperature within a normal soybean production field. Negative correlations were observed between the plant height and plant canopy temperature data obtained with the sensors. Plant height and plant temperature measurements were spatially correlated; the plant height had greater spatial continuity than the plant temperature measurements. Maps were easily developed showing plant height and plant canopy temperature distribution throughout the field. These results indicated that inexpensive ultrasonic and plant canopy temperature sensors based on an open-source platform can be used to study plant height and plant canopy temperature variability in soybeans. The sensors and techniques used this study can be easily adapted to other crops, thus providing two important layers for monitoring plant growth and potentially plant stress.

\section{Acknowledgements}

The authors would like to thank Milton Gaston Jr., David Thornton, Destraile Jackson, and Mekaela Brisco for their assistance in this study. Mention of a tradename, proprietary product, or specific equipment does not constitute a guarantee or warranty by the United States Department of Agriculture and does not apply endorsement of a product to the exclusion of others that may be suitable.

\section{Conflicts of Interest}

The authors declare no conflicts of interest regarding the publication of this paper.

\section{References}

[1] Jackson, R.D. (1982) Canopy Temperature and Crop Water Stress. Advances in Irrigation, 1, 43-85. https://doi.org/10.1016/B978-0-12-024301-3.50009-5

[2] Clawson, K.L., Jackson, R.D. and Pinter, P.J. (1989) Evaluating Plant Water Stress with Canopy Temperature Differences. Agronomy Journal, 81, 858-863. https://doi.org/10.2134/agronj1989.00021962008100060004x

[3] Rashid, A.J., Stark, C., Tanveer, A. and Mustafa, T. (1999) Use of Canopy Temper- 
ature Measurements as a Screening Tool for Drought Tolerance in Spring Wheat. Journal of Agronomy and Crop Science, 182, 231-237. https://doi.org/10.1046/j.1439-037x.1999.00335.x

[4] Portz, G., Amaral, L., Molin, J. and Adamchuk, V. (2013) Field Comparison of Ultrasonic and Canopy Reflectance Sensors Used to Estimate Biomass and N-Uptake in Sugarcane. Precision Agriculture 2013-Papers Presented at the 9th European Conference on Precision Agriculture, ECPA 2013, 111-117.

[5] Fisher, D.K. and Huang, Y. (2017) Mobile Open-Source Plant-Canopy Monitoring System. Modern Instrumentation, 6, 1-13. https://doi.org/10.4236/mi.2017.61001

[6] Sui, R. and Baggard, J. (2018) Center-Pivot-Mounted Sensing System for Monitoring Plant Height and Canopy Temperature. Transactions American Society of Agricultural and Biological Engineers, 61, 831-837.

https://doi.org/10.13031/trans.12506

[7] Scotford, I.M. and Miller, P.C.H. (2004) Combination of Spectral Reflectance and Ultrasonic Sensing to Monitor the Growth of Winter Wheat. Biosystems Engineering, 87, 27-38. https://doi.org/10.1016/j.biosystemseng.2003.09.009

[8] Chang, Y.K., Zaman, Q.U., Rehaman, T.U., Farooque, A.A., Esau, T. and Jameel, M.W. (2017) A Real-Time Ultrasonic System to Measure Wild Blueberry Plant Height during Harvesting. Biosystems Engineering, 157, 35-44. https://doi.org/10.1016/j.biosystemseng.2017.02.004

[9] Fisher, D.K. and Sui, R. (2013) An Inexpensive Open-Source Ultrasonic Sensing System for Monitoring Liquid Levels. Agricultural Engineering International: CIGR Journal, 15, 328-334.

[10] Bitella, G., Rossi, R., Bochicchio, R., Perniola, M. and Amato, M. (2014) A Novel Low-Cost Open-Hardware Platform for Monitoring Soil Water Content and Multiple Soil-Air-Vegetation Parameters. Sensors, 14, 19639-19659. https://doi.org/10.3390/s141019639

[11] Mesas-Carrascosa, F.J., VerdúSantano, D., Meroño, J.E., Sánchez de la Orden, M. and García-Ferrer, A. (2015) Open Source Hardware to Monitor Environmental Parameters in Precision Agriculture. Biosystems Engineering, 137, 73-83. https://doi.org/10.1016/j.biosystemseng.2015.07.005

[12] Trilles, S., Torres-Sospedra, J., Belmonte, O., Zarazaga-Soria, F.J., González-Pérez, A. and Huerta, J. (2019) Development of an Open Sensorized Platform in a Smart Agriculture Context: A Vineyard Support System for Monitoring Mildew Disease. Sustainable Computing. Informatics and Systems, 1-36. https://doi.org/10.1016/j.suscom.2019.01.011

[13] NOAA National Centers for Environmental Information, Climate at a Glance: County Time Series. https://www.ncdc.noaa.gov/cag/

[14] United States Department of Agriculture, National Agricultural Statistics Service. (2019) Washington County Mississippi, 2017 Census of Agriculture County Profile. 2.

[15] Rees, D.G. (2001) Essential Statistics. 4th Edition, Chapman and Hall/CRC, Boca Raton, FL.

[16] R Core Team (2019) R: A Language and Environment for Statistical Computing. R Foundation for Statistical Computing, Vienna, Austria. https://www.R-project.org/

[17] Oliver, M. and Webster, R. (2014) A Tutorial Guide to Geostatistics: Computing and Modelling Variograms and Kriging. Catena, 113, 56-69.

https://doi.org/10.1016/j.catena.2013.09.006 
[18] Oliver, M. and Webster, R. (2015) Basics Steps in Geostatistics: The Variogram and Kriging. Springer Briefs in Agriculture. Springer, Cham, Heidelberg, New York. https://doi.org/10.1007/978-3-319-15865-5

[19] QGIS Development Team (2019) QGIS Geographic Information System. Open Source Geospatial Foundation Project. http://qgis.osgeo.org

[20] Bai, G., Ge, Y., Hussain, W., Baenziger, P.S. and Graef, G. (2016) A Multi-Sensor System for High Throughput Field Phenotyping in Soybean and Wheat Breeding. Computers and Electronics in Agriculture, 128, 181-192. https://doi.org/10.1016/j.compag.2016.08.021

[21] Colaço, A.F., Molin, J.P., Rosell-Polo, J.R. and Escolà, A. (2019) Spatial Variability in Commercial Orange Groves. Part 1: Canopy Volume and Height. Precision Agriculture, 20, 788-804. https://doi.org/10.1007/s11119-018-9612-3 